\title{
Pressurized liquids as an alternative green process to obtain anti-inflammatory agents from rosemary, marjoram and basil
}

\author{
E. Arranz, E. Vázquez, L. Jaime, G. Reglero and S. Santoyo \\ Institute of Food Science Research (CIAL), Universidad Autónoma de Madrid, 28049, Madrid, Spain
}

Inflammation response protects the host against tissue injury and microbial invasion. As such, this response should be short-lived, and failing can result in pathogenesis of many immunity-related diseases ${ }^{(1,2)}$.

The aim of this work was to study the anti-inflammatory activity of different pressurized liquid extract (PLE) obtained from Rosmarinus officinalis, Origanum majorana and Ocimum basilicum. PLE is a technique based on the extraction at temperature and pressure high enough to maintain the solvent in a liquid state during the whole extraction procedure. To determinate the optimal antioxidant extract were used different extraction conditions and that was obtained as follows: $50 \%$ ethanol: $50 \%$ water as solvent, $150{ }^{\circ} \mathrm{C}$ as extraction temperature and 10 minutes as static time. THP- 1 macrophages activated by lipopolysaccharide (LPS) $(0.05 \mu \mathrm{g} / \mathrm{mL})$ or human oxidized-LDL (ox-LDL) $(75 \mu \mathrm{g} / \mathrm{mL})$ were treated with 10,15 and $25 \mu \mathrm{g} / \mathrm{mL}$ of extracts during 24 hours. The secretion and gene expression of several inflammatory mediators (TNF- $\alpha$, IL-1 $\beta$, IL-6 and IL-10) was measured with ELISA kits and relative quantification in qPCR respectively. All experiments were made with three biological replicates.

Rosemary extract was the most active, since $10 \mu \mathrm{g} / \mathrm{mL}$ of this extract reduce the secretion of TNF- $\alpha$, IL- $1 \beta$ and IL- 6 , proinflammatory cytokines, in cells activated with LPS or oxLDL. Although in cells activated with ox-LDL, this reduction was highest in IL-1 $\beta$ secretion. Also marjoram and basil reduced the secretion of the analyzed proinflammatory cytokines but less than rosemary. Using $25 \mu \mathrm{g} / \mathrm{mL}$ of marjoram or basil the secretion of TNF- $\alpha$ was reduced until $25 \%$ while the same amount of rosemary reduced it until $80 \%$ in cells activated with LPS because in cells activated with ox-LDL there was less difference. In either case were found significant differences in IL-10 secretion, an anti-inflammatory cytokine. The results obtained in gene expression also showed a decrease in proinflammatory cytokines, being more pronounced in the case of rosemary, corroborating what was obtained in the measurement of the secretion.

In conclusion, this technique could be used as an alternative green process to obtained extracts with an important anti-inflammatory activity. Thus rosemary, marjoram and basil pressurized liquid extract could be proposed as a food ingredients with anti-inflammatory properties.

1. Pulendran B, Palucka K \& Banchereau J (2001) Science 293, 253-256.

2. Steinman L (2004) Science 305, 212-216. 